\title{
Diagnóstico temporal e espacial da qualidade da água superficial em uma microbacia urbana
}

\begin{abstract}
O desenvolvimento urbano e a ocupação desordenada do solo provocam alteraç̃os tanto na quantidade, quanto na qualidade dos recursos hídricos em uma bacia hidrográfica. Neste contexto, o objetivo deste estudo consiste na caracterizacão da variação sazonal e espacial da qualidade da água superficial do Córrego Fortaleza, situado no município de Cuiabá (MT). 0 monitoramento foi realizado em três pontos de coleta: Nascente, Meio e Exutório. As coletas foram realizadas mensalmente, entre junho/2017 e março/2018, nos períodos de seca e chuva. São apresentados os resultados obtidos ao longo do tempo para os seguintes parâmetros físicos, químicos e microbiológicos: Temperatura, Sólidos Totais Dissolvidos (STD), Condutividade Elétrica (CE), pH, Oxigênio Dissolvido (OD), Cor Verdadeira, Turbidez, Sólidos Totais, Demanda Bioquímica de Oxigênio (DBO5), Demanda Química de Oxigênio (DQO), Alcalinidade, Nitrito, Nitrato, Nitrogênio Total, Fósforo Total, Coliformes Totais (CT) e Escherichia coli. Os dados foram tratados estatisticamente, de forma descritiva com o auxílio do software de análise de dados 'R' e com a aplicação da correlação de Pearson. Para a classificação da qualidade da água nos pontos analisados, realizou-se o cálculo do Índice de Qualidade da Água (IQA-CETESB). Os resultados demonstraram a influência da sazonalidade principalmente sobre os parâmetros Cor Verdadeira, DBO5, Nitrogênio Total, Fósforo Total, e Escherichia coli. As fortes correlações entre STDxCE e CTxE. coli ratificam a as alterações na qualidade da água advindas de atividades antrópicas na microbacia. Por fim, o IQA-CETESB classificou a qualidade do ponto Nascente como 'razoável' e dos pontos Meio e Exutório como 'ruim', apontando que a água superficial do Córrego Fortaleza se encontra seriamente alterada devido, principalmente, ao processo de uso e ocupação inadequados do solo.
\end{abstract}

Palavras-chave: Gestão de Recursos Hídricos; Uso e Ocupação do Solo; IQA; Correlação de Pearson.

\section{Temporal and spatial diagnosis of surface water quality in an urban watershed}

Urban development and disorderly land use change both the quantity and quality of water resources in a watershed. In this context, the objective of this study is to characterize the seasona and spatial variation of the surface water quality of the Fortaleza Stream, located in Cuiabá (MT). Monitoring was carried out at three collection points: East, Middle and Exutory. The collections were performed monthly, between june/2017 and march/2018, during the dry and rain periods. The results obtained over time are presented for the following physical, chemical and microbiological parameters: Temperature, Total Dissolved Solids (STD), Electrical Conductivity (EC), pH, Dissolved Oxygen (OD), True Color, Turbidity, Total Solids, Biochemical Oxygen Demand (BOD5), Chemical Oxygen Demand (COD), Alkalinity, Nitrite, Nitrate, Total Nitrogen, Total Phosphorus, Total Coliforms (CT) and Escherichia coli. Data were treated statistically, descriptively with the aid of data analysis software ' $R$ ' and the application of Pearson correlation. To classify the water quality in the analyzed points, the Water Quality Index (IQA-CETESB) was calculated. The results demonstrated the influence of seasonality mainly on True Color, BOD5, Total Nitrogen, Total Phosphorus, and Escherichia coli parameters. The strong correlations between STDxCE and CTxE. coli ratifies the changes in water quality resulting from anthropogenic activities in the watershed. Finally, the IQA-CETESB classified the quality of the Rising poin as 'reasonable' and the Middle and Exutory points as 'bad', pointing out that the surface water of Fortaleza Stream is seriously altered mainly due to the use and occupation process. inadequate soil.

Keywords: Water Resources Management; Land Use and Occupation; IQA; Pearson correlation.

Topic: Engenharia de Recursos Hídricos

Reviewed anonymously in the process of blind peer.

Eduarda da Conceição Oliveira (iD)

Universidade Federal de Mato Grosso, Brasil

http://lattes.cnpq.br/2652360250917635

http://orcid.org/0000-0001-9184-0627

eduarda.ambiental@gmail.com

Karytany Ulian Dalla Costa (1D

Universidade Federal de Mato Grosso, Brasil

http://lattes.cnpq.br/3340400763795544

karytany @hotmail.com

Wilhan Douglas dos Reis (D)

Universidade Federal do Mato Grosso, Brasil

http://lattes.cnpq.br/3340400763795544

wilhan_cba@hotmail.com

d

DOI: 10.6008/CBPC2179-6858.2018.008.0006
Received: 03/10/2018

Approved: 03/11/2018
Aldecy de Almeida Santos

Universidade Federal de Mato Grosso, Brasi

http://lattes.cnpq.br/3224921282419849

aldecy_allmeida@yahoo.com.br

Welitom Ttatom Pereira da Silva (iD)

Universidade Federal do Mato Grosso do Sul, Brasil

http://lattes.cnpq.br/0393291558712119

wttatom@terra.com.br

Referencing this:

OLIVEIRA, E. C.; COSTA, K. U. D.; REIS, W. D.; SANTOS, A. A.; SILVA, W. T. P.. Diagnóstico temporal e espacial da qualidade da água superficial em uma microbacia urbana. Revista Ibero-Americana de Ciências Ambientais, v.9, n.8, p.57-69, 2018. DOI:

http://doi.org/10.6008/CBPC2179-6858.2018.008.0006 


\section{INTRODUÇÃO}

A ocupação desordenada do solo provoca alterações na quantidade, na qualidade e no regime dos corpos de água, bem como induz a poluição dos recursos hídricos (SOUZA et al., 2014). O processo de uso e ocupação do solo é objeto de vários estudos que comprovam a relação entre ao aumento da pressão das atividades antrópicas e a deterioração da qualidade das águas (YU et al., 2013, FIA et al., 2015, MENEZES et al., 2016).

No que se refere às alterações na qualidade de corpos d'água, as principais fontes de poluição decorrentes do processo de urbanização, conforme Castro et al. (2009), são o lançamento de esgoto sanitário in natura, efluentes industriais, os dejetos de animais, os resíduos sólidos, os canteiros de obras, a erosão dos solos, a vegetação e a poluição atmosférica. Souza et al. (2014) e Souza et al. (2015) salientam que essas alterações, quando ocorridas em uma bacia hidrográfica, podem ser avaliadas através do monitoramento da qualidade das águas superficiais, uma vez que o comportamento da qualidade da água reflete as condições e atividades antrópicas realizadas na bacia.

Diante disso, Fia et al. (2015) ressalta que o monitoramento das águas superficiais é um importante instrumento de gestão, uma vez que propicia a obtenção de dados quali-quantitativos da água, em função de seus usos previstos, a fim de possibilitar a tomada de decisão por parte dos órgãos ambientais. Dentre as ferramentas de gestão e monitoramento, destaca-se o IQA (Índice de Qualidade da Água), o qual é capaz de traduzir os parâmetros de qualidade de um dado corpo hídrico reunindo-os em um único índice, usado para classificar sua qualidade, que pode variar de boa a ruim (MEDEIROS et al., 2016).

Em Cuiabá, os principais problemas advindos da ocupação urbana são as deficiências no sistema de esgotamento sanitário, destinação inadequada de resíduos sólidos e questões ambientais ligadas principalmente ao Rio Cuiabá (GARCIA, 2010). A microbacia do Córrego Fortaleza abriga 6 bairros da região sul de Cuiabá, onde existem residências que não são atendidas pela rede geral de esgotamento sanitário, e por isso, muitos moradores utilizam poços para o seu abastecimento e fossas para descarte de esgotos in natura. Neste contexto, este trabalho teve por objetivo caracterizar a variação sazonal e espacial da qualidade da água superficial do Córrego Fortaleza, a fim de identificar os principais impactos advindos do processo inadequado de urbanização local, com vistas ao subsídio de melhores métodos gestão para prevenção e adequação dos impactos ambientais sobre a qualidade da água.

\section{MATERIAIS E MÉTODOS}

\section{Caracterização da Área de Estudo}

A microbacia do Córrego Fortaleza, é uma sub-bacia do Rio Coxipó, que por sua vez, integra a Bacia do Rio Cuiabá, e está situada no perímetro urbano de Cuiabá (MT), na Região Sul. Possui área de 3,43km², perímetro total de $12,86 \mathrm{~km}$ e o seu canal principal possui $4,88 \mathrm{~km}$ de extensão. $\mathrm{O}$ clima da região, segundo a classificação climática de Koppen, é do tipo Aw - Clima de Savana, caracterizado como Tropical Semiúmido, marcado por dois períodos bem distintos: a estiagem (abril a setembro) e chuvoso (outubro a março). A 
temperatura média anual é $26^{\circ} \mathrm{C}$, com as máximas médias diárias em torno de $36^{\circ} \mathrm{C}$, em setembro, e as mínimas de $15^{\circ} \mathrm{C}$, em junho (MATO GROSSO, 2016). De acordo com Almeida et al. (2011) e Chiaranda et al. (2016), a precipitação média anual na região é $1387,7 \mathrm{~mm}$, sendo o trimestre mais chuvoso correspondente aos meses de dezembro, janeiro e fevereiro, e o trimestre mais seco correspondente aos meses de junho, julho e agosto.

Foram realizadas campanhas de amostragem de água durante o período de jun/2017 a mar/2018, compreendendo as duas estações (estiagem e chuvosa), em 3 pontos de coleta, denominados Nascente (N), Meio (M) e Exutório (E), conforme apresentado na figura 1. A descrição dos pontos pode ser observada na tabela 1. A coleta e preservação das amostras foram realizadas de acordo com CETESB (2011), sendo todas as amostragens coletadas em triplicata. Os métodos de análise das amostras seguiram o que determina APHA (2012) (tabela 2).

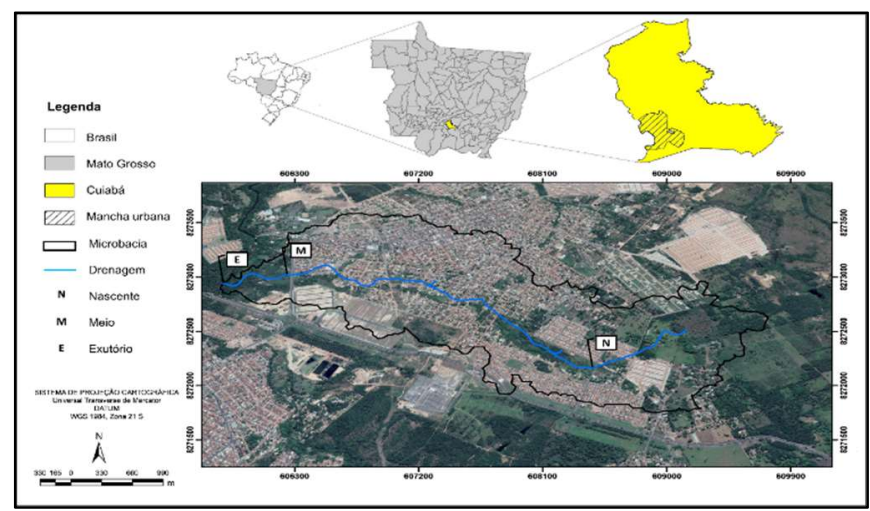

Figura 1: Pontos de coleta de água superficial e subterrânea no Córrego Fortaleza, Cuiabá (MT).

Tabela 1: Descrição e coordenadas geográficas dos pontos de amostragem de água superficial na microbacia do Córrego Fortaleza, Cuiabá (MT).

\begin{tabular}{|c|c|c|c|}
\hline \multirow{2}{*}{ Pontos } & $\mathbf{X}(\mathbf{m})$ & \multirow{2}{*}{ Coord. UTM* } & \multirow{2}{*}{ Descrição } \\
\cline { 2 - 3 } & 608446,636952 & 8272166,57317 & Nascente \\
\hline $\mathrm{N}$ & 606169,414321 & 8272994,70358 & Meio \\
\hline $\mathrm{M}$ & 605785,145987 & 8272971,90511 & Exutório \\
\hline
\end{tabular}

Legenda: *Datum WGS1984. Fuso 21S.

Tabela 2: Parâmetros de qualidade da água analisados, metodologias e unidades, segundo APHA (2012).

\begin{tabular}{|c|c|c|}
\hline Parâmetro de qualidade da água & Metodologia Analítica & Unidade \\
\hline Temperatura do ar & \multirow{2}{*}{ Termométrico } & \multirow{2}{*}{${ }^{\circ} \mathrm{C}$} \\
\hline Temperatura da água & & \\
\hline Sólidos totais dissolvidos & \multirow{3}{*}{ Potenciométrico } & $\mathrm{mg} \mathrm{L}^{-1}$ \\
\hline Condutividade elétrica & & $\mu \mathrm{S} \mathrm{cm}-1$ \\
\hline $\mathrm{pH}$ & & - \\
\hline Oxigênio dissolvido & Oxímetro & $\mathrm{mg} \mathrm{L}^{-1}$ \\
\hline Cor verdadeira & Colorimétrico & $\mathrm{mg} \mathrm{PtCo} \mathrm{L}^{-1}$ \\
\hline Turbidez & Nefelométrico & NTU \\
\hline Sólidos totais & Gravimétrico & \multirow{6}{*}{$\mathrm{mg} \mathrm{L}^{-1}$} \\
\hline $\mathrm{DBO}_{5}$ & Winkler & \\
\hline Alcalinidade & \multirow{2}{*}{ Titulométrico } & \\
\hline Dureza & & \\
\hline Nitrito & \multirow{2}{*}{ Cromatografia iônica } & \\
\hline Nitrato & & \\
\hline Coliformes Totais & \multirow{2}{*}{ Método Substrato Cromogênico - Colilert ${ }^{\circledR}$} & \multirow{2}{*}{$\mathrm{NMP} 100 \mathrm{~mL}^{-1}$} \\
\hline E. coli & & \\
\hline
\end{tabular}

Os parâmetros Temperatura, Sólidos Totais Dissolvidos (STD), Condutividade Elétrica (CE), pH e 
Oxigênio Dissolvido (OD) foram determinadas in loco. As análises dos demais parâmetros foram realizadas no Laboratório de Análises Físico-químicas e no Laboratório de Microbiologia Sanitária e Ambiental, ambos do Departamento de Engenharia Sanitária e Ambiental da Universidade Federal de Mato Grosso - UFMT.

As variações espaciais e temporais dos parâmetros de qualidade avaliados foram analisadas e tratadas estatisticamente, de forma descritiva. Com o auxílio do software de análise de dados ' $R$ ', versão 3.5.1 foram construídos boxplots com intervalo de confiança de $95 \%$. Para a avaliação das relações entre os parâmetros de qualidade em cada estação, foi gerada a matriz de correlação de Pearson ( $r$ ), por meio da ferramenta Excel 2013, a fim de analisar as relações entre os parâmetros de qualidade da água na estação seca e na estação chuvosa.

De acordo com Menezes et al. (2014), a correlação de Pearson expressa a importância linear de duas ou mais pelos intervalos dos coeficientes $(-1,1)$, sendo que quanto mais próximo dos extremos deste intervalo, maior é a correlação entre as variáveis. Ainda segundo os autores, o coeficiente positivo sugere que as variáveis variam juntas no mesmo sentido, enquanto o coeficiente negativo indica que elas variam em sentido contrário. Quando duas variáveis são estatisticamente independentes, o coeficiente de correlação linear é igual a zero $(r=0)$. Após o tratamento dos dados, determinou-se a qualidade da água superficial do Córrego Fortaleza por meio do Índice de Qualidade da Água (IQA-CETESB), de acordo com as faixas de IQA para Mato Grosso: Ótima (91 a 100); Boa (71 a 90); Razoável (51 a 70); Ruim (26 a 50); e Péssima (0 a 25) (MATO GROSSO, 2016).

\section{RESULTADOS E DISCUSSÃO}

\section{Análise da qualidade da água e estatística descritiva}

A figura 2 apresenta os Boxplots dos parâmetros temperatura, sólidos totais dissolvidos, condutividade elétrica, sólidos totais, cor e turbidez. Conforme os dados apresentados na figura 2, percebese que os três pontos amostrais apresentaram valores mais elevados de temperatura durante o período de estiagem na nascente $\left(29^{\circ} \mathrm{C}\right)$, e menores valores durante o período chuvoso, no meio e no exutório (21 e 23 ${ }^{\circ} \mathrm{C}$, respectivamente). Menezes et al. (2016) encontrou resultados semelhantes e explicam que essa relação ocorre devido ao fato de que corpos d'água pouco profundos sofrem forte influência da temperatura ambiente na temperatura da água.

As variações dos parâmetros STD e CE (figura 2) mostram que estes se apresentaram menores na nascente e maiores no meio e no exutório. Os maiores valores encontrados para os dois parâmetros foram registrados no período de estiagem, com STD de 214 e $204 \mathrm{mg} \mathrm{L}^{-1}$ e CE de 429 e $384 \mu \mathrm{s} \mathrm{cm-1}$, para o meio e exutório, respectivamente. De acordo com Jordão et al. (2014), baixas vazões favorecem a concentração de poluentes nos cursos d'água. Essa afirmação corrobora o fato de as maiores concentrações de STD e CE terem sido registradas no período de menor precipitação na região (período de estiagem). 


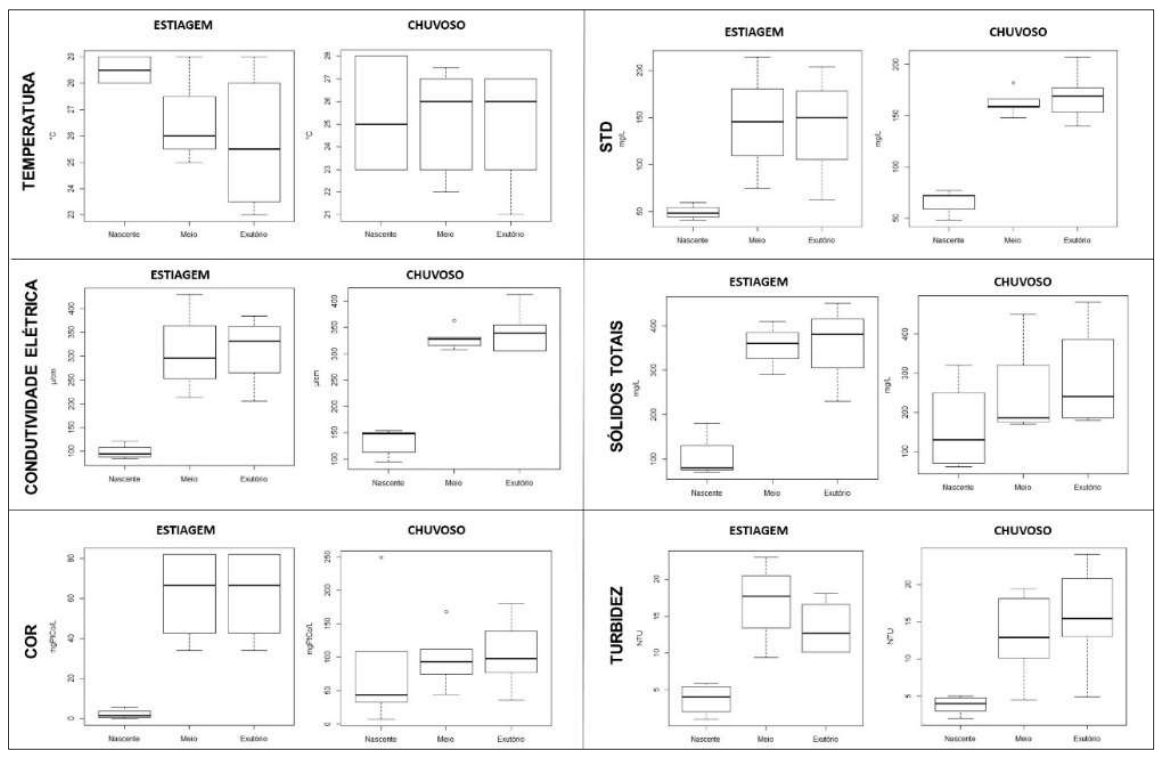

Figura 2: Boxplots dos parâmetros físicos analisados na microbacia do Córrego Fortaleza coletados no período de junho/2017 a fevereiro/2018.

Ressalta-se que todas concentrações de STD registradas se encontraram em conformidade com o valor máximo permitido para em corpos d'água de Classe 2, estabelecido pela Resolução CONAMA № 357/2005 (500 $\left.\mathrm{mg} \mathrm{L}^{-1}\right)$. Para Sólidos Totais, conforme se propôs na figura 2, as concentrações variaram de $60 \mathrm{mg} \mathrm{L}^{-1}$ (nascente) a 480 $\mathrm{mg} \mathrm{L}^{-1}$ (exutório). Houve um decréscimo nas variações de sólidos totais entre jul/17 e out/17. Após o início das chuvas (out/17), percebe-se que esses valores apresentaram tendência crescente, confirmando o que foi descrito por Medeiros et al. (2016), que durante as chuvas a concentração de sólidos em suspensão aumenta consideravelmente.

No período de estiagem, os valores de cor verdadeira estiveram em acordo com o padrão estabelecido pela Resolução CONAMA № 357/2005 (75 $\left.\mathrm{mgPtCo} \mathrm{L}^{-1}\right)$, com exceção do ponto amostral do meio do córrego, com valores levemente superiores ao permitido (figura 2). Porém no período de chuvas observou-se que, nos três pontos amostrais, o limite foi ultrapassado. Piratoba et al. (2017) explica que com o aumento das chuvas, aumenta também o transporte de material orgânico e inorgânico drenado nas margens dos rios, o que influencia um aumento na cor. Richter (2009), salienta que os ácidos húmicos, proveniente da decomposição de vegetais, influencia diretamente a cor dos corpos d'água.

No tocante à Turbidez, observou-se que todos os valores estiveram em conformidade com a Resolução CONAMA nำ357/2005. O maior valor encontrado (18,1NTU) foi registrado no início do período chuvoso, no exutório do córrego. Esse fato pode ser explicado em razão dos novos empreendimentos imobiliários que vêm sendo construídos ao longo da microbacia, o que ocasiona maior propensão ao arraste de sedimentos pelas águas de chuva.

Medeiros et al. (2016) também encontrou valores de turbidez semelhantes no Riacho da Bica, Portalegre (RN), que variaram de 2,4NTU na estiagem, a 18NTU no período chuvoso. Medeiros et al. (2016) destacou que durante as chuvas a concentração de sólidos em suspensão aumenta consideravelmente, acarretando o aumento da turbidez de corpos d'água. As variações dos parâmetros pH, OD, $\mathrm{DBO}_{5}$ e $\mathrm{DQO}$ analisados durante o período de monitoramento estão apresentadas na figura 3. 


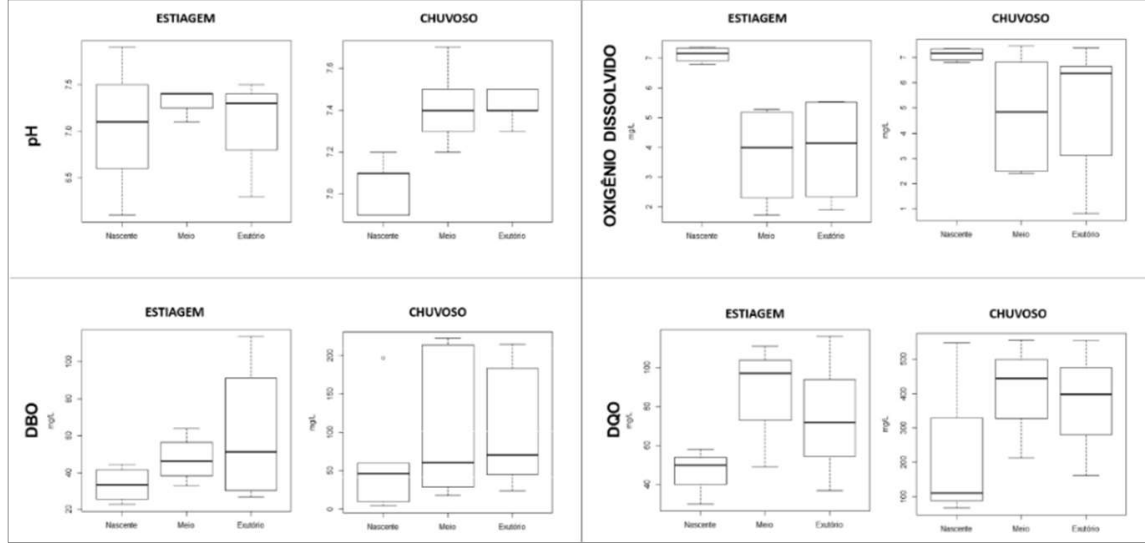

Figura 3: Boxplots dos parâmetros $\mathrm{pH}, \mathrm{OD}, \mathrm{DBO}_{5}$ e $\mathrm{DQO}$ analisados na microbacia do Córrego Fortaleza coletados no período de junho/2017 a fevereiro/2018.

Os valores de pH não apresentaram variações significativas entre os períodos de estiagem e de chuvas, variando de 6,1 a 7,2 na nascente; e 7,1 a 7,7 no meio; e 6,3 a 7,5 no exutório. Em todas as amostragens, os valores estiveram dentro dos limites permitidos pela Resolução CONAMA № 357/2005 (6 a 9).

A maiores concentrações de OD foram registradas na nascente em todo o período de monitoramento, em contraste com os valores encontrados no meio e no exutório do córrego, chegando a concentrações mínimas de $1,72 \mathrm{mg} \mathrm{L}^{-1}$ durante a estiagem. Em contraste com a nascente, os pontos meio e exutório apresentaram, durante o período de estiagem, concentrações de OD muito abaixo do valor mínimo fixado pela Resolução CONAMA № 357/2005 (5 mg L-1).

Barros et al. (2011) encontrou valores semelhantes no Córrego André, em Mirassol do Oeste (MT), com valores entre $1,07 \mathrm{mg} \mathrm{L}^{-1}$ no período de estiagem a $5,6 \mathrm{mg} \mathrm{L}^{-1}$ no período de chuvoso. De acordo com Barros et al. (2011), a baixa quantidade de OD nos corpos d'água está relacionada ao lançamento de esgoto sem tratamento nos corpos d'água em microbacias hidrográficas urbanizadas e ao menor potencial de autodepuração devido às baixas vazões observadas na estiagem.

As concentrações médias de $\mathrm{DBO}_{5}$ foram $50,2 \mathrm{mg} \mathrm{L}^{-1}$ (nascente), $81,3 \mathrm{mg} \mathrm{L}^{-1}$ (meio) e $86,7 \mathrm{mg} \mathrm{L}^{-1}$ (exutório). Em todas as amostragens, as concentrações deste parâmetro estiveram em desacordo com o limite máximo estabelecido pela Resolução CONAMA no 357/2005 (5 $\left.\mathrm{mg} \mathrm{L}^{-1}\right)$. As maiores concentrações foram registradas durante o período chuvoso, sendo a concentração máxima $221,7 \mathrm{mg} \mathrm{L}^{-1}$ para o ponto meio do córrego.

Amorim et al. (2017) e Vaz et al. (2014) encontraram situação semelhante, e explicam que esse fato pode ser decorrente do aumento da carga de matéria orgânica durante os eventos de precipitação pluviométrica, em consequência da "lavagem de superfícies". Para Medeiros et al. (2016), valores significativos de $\mathrm{DBO}_{5}$ podem estar relacionados à interferência antrópica local, a qual se caracteriza pelo uso e ocupação indevidos do solo e pela disposição de efluentes domésticos in natura no manancial.

Os valores de $\mathrm{DQO}$ seguiram o mesmo padrão dos valores de $\mathrm{DBO}_{5}$, aumentando significativamente no período de chuvoso. A DQO não possui limite padrão definido pela Resolução CONAMA № 357/2005, entretanto pode-se observar que seus valores são mais elevados no meio e no exutório do Córrego, com o 
valor mais alto sendo registado no exutório $\left(555 \mathrm{mg} \mathrm{L}^{-1}\right)$. Esse fato pode ser explicado pelo uso e ocupação do solo ao longo do córrego, onde percebe-se aumento da carga de poluição, sobretudo de efluentes domésticos, e também lançamentos de resíduos sólidos.

Em relação ao parâmetro Alcalinidade (figura 4), na nascente ocorreram valores semelhantes em todas as campanhas de amostragem, com concentração média de $39 \mathrm{mg} \mathrm{L}^{-1}$. Já para os pontos do meio e do exutório do Córrego, as concentrações se mostraram bastante elevadas em relação à nascente, com concentrações médias de 131 e $145 \mathrm{mg} \mathrm{L}^{-1}$, respectivamente e maiores valores registrados no período de estiagem, corroborando com os resultados de Piratoba et al. (2017).

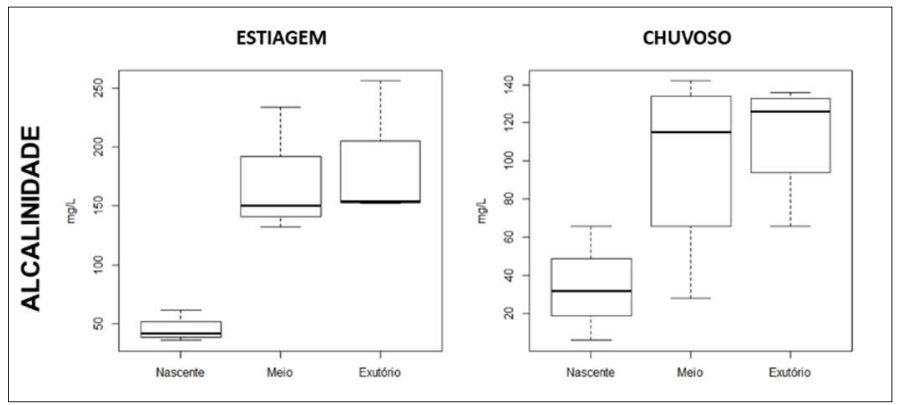

Figura 4: Boxplots do parâmetro Alcalinidade analisado na microbacia do Córrego Fortaleza coletados no período de junho/2017 a fevereiro/2018.

As variações dos parâmetros Nitrito, Nitrato, Nitrogênio Total e Fósforo Total estão apresentadas na figura 5. Durante o período de monitoramento, a maior concentração de nitrito foi encontrada na nascente, com $0,041 \mathrm{mg} \mathrm{L}^{-1}$, em ago/17. Nota-se que este valor não ultrapassa o estabelecido pela Resolução CONAMA no $357 / 2005$, rios de Classe 2, $\left(1,0 \mathrm{mg} \mathrm{L}^{-1}\right)$.

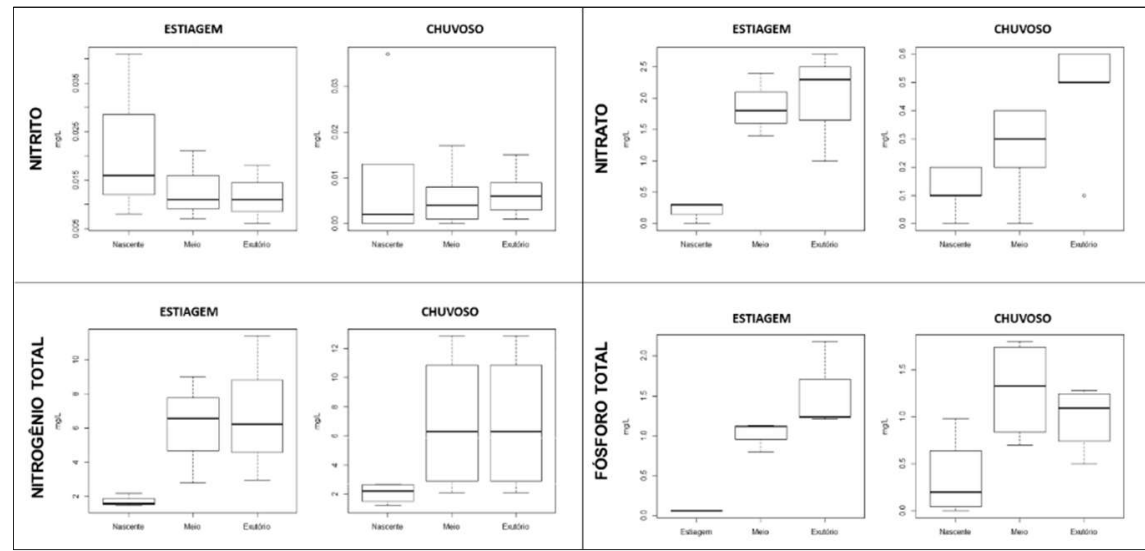

Figura 5: Boxplots dos parâmetros Nitrito, Nitrato, Nitrogênio Total e Fósforo Total analisados na microbacia do Córrego Fortaleza coletados no período de junho/2017 a fevereiro/2018.

As concentrações de nitrato variaram entre $0,1 \mathrm{mg} \mathrm{L}^{-1}$ na nascente e $2,7 \mathrm{mg} \mathrm{L}^{-1}$ no exutório. $\mathrm{O}$ limite máximo para esta variável estabelecido pela Resolução CONAMA no 357/2005 (10 g L $^{-1}$ ) não foi ultrapassado nas amostras avaliadas. Os valores médios de nitrato encontrados na nascente, no meio e no exutório do Córrego Fortaleza foram de 0,17; 0,93 e 1,11 $\mathrm{mg} \mathrm{L}^{-1}$, respectivamente. As concentrações de nitrogênio total ao longo das análises nos pontos amostrais, apresentou elevações nos valores, principalmente no período 
de estiagem, sobretudo entre jul e ago/17. Souza et al. (2014) ressalta que elevadas concentrações de nitrogênio indicam a poluição orgânica no curso d'água.

Em relação ao fósforo total, a Resolução CONAMA no 357/2005, estabelece o valor máximo permitido em cursos d'água de Classe 2 (ambiente lótico) de $0,1 \mathrm{mg} \mathrm{L}^{-1}$. O menor valor registrado foi $0,06 \mathrm{mg} \mathrm{L}^{-1}$ na nascente e maior valor registrado foi 2,18 $\mathrm{mg} \mathrm{L}^{-1}$, no exutório do Córrego. Durante o período de estiagem, o exutório apresentou concentrações maiores de fósforo que o ponto meio. Já no período chuvoso, o ponto meio apresentou concentrações maiores que o exutório.

Coradi et al. (2009) salienta que elevadas concentrações de nitrogênio associadas às de fósforo podem vir a causar desenvolvimento exagerado do fito e zooplâncton, levando ao processo de eutrofização, uma vez que o fósforo é essencial para o crescimento de organismos e pode ser o nutriente que limita a produtividade primária de um corpo de água. Para as variações de coliformes totais e $E$. coli, os resultados estão apresentados na figura 6.

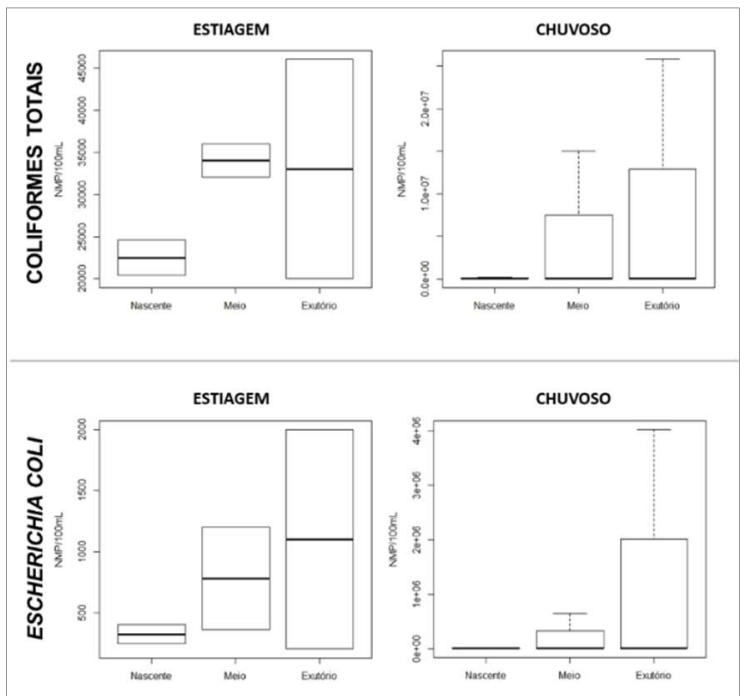

Figura 6: Boxplots dos parâmetros microbiológicos analisados nos pontos amostrais do Córrego Fortaleza, Cuiabá-MT coletados no período de junho/2017 a março/2018.

Quanto aos valores de Coliformes Totais e E. coli, observa-se que as menores concentrações ocorreram na nascente do córrego, com exceção da amostragem realizada em jul/17, no qual a concentração de $E$. coli na nascente foi maior que no meio e que no exutório. Para $E$. coli, somente no mês de jul/17, as concentrações nos três pontos amostrais obedeceram ao padrão estabelecido pela Resolução CONAMA no 357/2005 para água Classe 2 (1000NMP.100 $\mathrm{mL}^{-1}$ ), e em março/2018, somente a nascente apresentou concentração dentro do limite padrão.

\section{Correlação de Pearson}

Para a análise dos coeficientes de correlação de Pearson foi considerada a classificação de CallegariJacques (2003): Correlação moderada $(0,3 \leq r<0,6)$, Correlação forte $(0,6 \leq r<0,9)$, Correlação muito forte $(r \geq 0,9)$. Para este estudo, foram considerados como não significativos coeficientes com a relação $r<0,3$. Todos os parâmetros analisados apresentaram correlação superior a 0,6 com pelo menos três outros 
parâmetros. As tabelas 3 a 5 contêm os dados da análise estatística do coeficiente de Pearson para os pontos

Nascente, Meio e Exutório em períodos de estiagem e chuvoso.

Tabela 3: Matriz de correlação de Pearson e coeficientes significativos para os parâmetros de qualidade da água da Nascente do Córrego Fortaleza. Apenas correlações fortes e muito fortes positivas $(r \geq 0,6)$.

\begin{tabular}{|c|c|c|c|c|c|c|c|c|c|c|c|c|c|c|c|c|c|c|}
\hline & & $T$ & STD & $C E$ & $S T$ & Cor & Turb & $p H$ & $O D$ & $D B O$ & $D Q O$ & $A / c$ & $\mathrm{NO}_{2}^{-}$ & $\mathrm{NO}_{3}^{-}$ & $N T$ & $F T$ & $C T$ & E. Coli \\
\hline \multirow{2}{*}{$T$} & $E$ & 1,00 & & & & & & & & & & & & & & & & \\
\hline & $C$ & 1,00 & & & & & & & & & & & & & & & & \\
\hline \multirow{2}{*}{ STD } & $E$ & - & 1,00 & & & & & & & & & & & & & & & \\
\hline & $C$ & - & 1,00 & & & & & & & & & & & & & & & \\
\hline \multirow{2}{*}{$C E$} & $E$ & - & 0,98 & 1,00 & & & & & & & & & & & & & & \\
\hline & $C$ & - & 0,99 & 1,00 & & & & & & & & & & & & & & \\
\hline \multirow{2}{*}{$S T$} & $E$ & - & - & - & 1,00 & & & & & & & & & & & & & \\
\hline & $C$ & - & 0,71 & 0,78 & 1,00 & & & & & & & & & & & & & \\
\hline \multirow{2}{*}{ Cor } & $E$ & - & 0,72 & 0,83 & - & 1,00 & & & & & & & & & & & & \\
\hline & $C$ & - & - & - & - & 1,00 & & & & & & & & & & & & \\
\hline \multirow{2}{*}{ Turb } & $E$ & - & - & 0,70 & - & 0,75 & 1,00 & & & & & & & & & & & \\
\hline & $C$ & - & 0,98 & 0,99 & 0,69 & - & 1,00 & & & & & & & & & & & \\
\hline \multirow{2}{*}{$p H$} & $E$ & - & - & - & - & - & - & 1,00 & & & & & & & & & & \\
\hline & $C$ & 0,61 & - & - & - & - & - & 1,00 & & & & & & & & & & \\
\hline \multirow{2}{*}{$O D$} & $E$ & - & - & - & - & - & - & - & 1,00 & & & & & & & & & \\
\hline & $C$ & - & - & - & - & - & - & - & 1,00 & & & & & & & & & \\
\hline \multirow{2}{*}{$D B O$} & $E$ & - & - & - & - & - & 0,91 & - & - & 1,00 & & & & & & & & \\
\hline & $C$ & - & - & - & - & - & - & - & - & 1,00 & & & & & & & & \\
\hline \multirow{2}{*}{$D Q O$} & $E$ & 0,96 & - & - & - & 0,97 & 0,65 & - & - & - & 1,00 & & & & & & & \\
\hline & $C$ & - & - & - & - & - & - & - & - & 0,99 & 1,00 & & & & & & & \\
\hline \multirow{2}{*}{ Alc } & $E$ & - & - & 0,79 & - & - & 0,77 & - & - & 0,89 & - & 1,00 & & & & & & \\
\hline & $C$ & - & 0,71 & 0,74 & 0,86 & - & 0,69 & - & - & - & - & 1,00 & & & & & & \\
\hline \multirow{2}{*}{$\mathrm{NO}_{2}^{-}$} & $E$ & 0,69 & - & - & - & - & 0,97 & - & - & 1,00 & - & 0,90 & 1,00 & & & & & \\
\hline & $C$ & - & - & - & 0,95 & - & - & - & - & - & - & 0,89 & 1,00 & & & & & \\
\hline \multirow{2}{*}{$\mathrm{NO}_{3}^{-}$} & $E$ & - & - & - & - & - & - & 0,90 & 0,99 & - & - & - & - & 1,00 & & & & \\
\hline & $C$ & - & - & - & - & - & - & - & 0,84 & 0,65 & - & - & - & 1,00 & & & & \\
\hline \multirow{2}{*}{$N T$} & $E$ & 0,63 & - & - & - & 0,93 & - & 0,74 & - & - & 0,82 & - & - & - & 1,00 & & & \\
\hline & $C$ & 0,77 & - & - & - & - & - & - & 0,70 & - & - & - & - & - & 1,00 & & & \\
\hline \multirow{2}{*}{$F T$} & $E$ & - & - & - & - & - & 0,89 & - & - & 0,97 & - & 0,98 & 0,97 & - & - & 1,00 & & \\
\hline & $C$ & 0,86 & - & - & - & - & - & 0,91 & - & - & - & - & - & - & - & 1,00 & & \\
\hline \multirow{2}{*}{$C T$} & $E$ & 0,87 & - & - & - & 1,00 & - & - & - & - & 0,97 & - & - & - & $0,-93$ & - & 1,00 & \\
\hline & $C$ & - & - & - & - & - & - & - & - & - & 1,00 & - & 1,00 & - & - & 1,00 & 1,00 & \\
\hline \multirow{2}{*}{ E. Coli } & $E$ & - & 0,92 & 0,77 & 0,82 & - & - & - & - & - & - & - & - & - & - & - & - & 1,00 \\
\hline & $C$ & - & - & - & - & - & - & - & 0,88 & 0,76 & 1,00 & - & - & 1,00 & - & 1,00 & - & 1,00 \\
\hline
\end{tabular}

Legendas: E: Estiagem; C: Chuvoso; T: Temperatura; STD: Sólidos Dissolvidos Totais; CE: Condutividade Elétrica; ST: Sólidos Totais; Turb: Turbidez; OD: Oxigênio Dissolvido; $\mathrm{DBO}_{5}$ : Demanda Bioquímica de Oxigênio; DQO: Demanda Química de Oxigênio; Alc: Alcalinidade; $\mathrm{NO}_{2}$ : Nitrito, $\mathrm{NO}_{3}$ : Nitrato; $\mathrm{NT}$ : Nitrogênio Total; FT: Fósforo Total; $\mathrm{CT}$ : Coliformes Totais.

Ao avaliar os dados obtidos através das correlações de Pearson no ponto Nascente, nota-se que para o período estiagem, dos 136 coeficientes, 76,5\% apresentaram valores significativos, sendo que destes, $32,7 \%$ apresentaram correlações fortes entre si $(0,6 \leq r<0,9)$ e $34,6 \%$ apresentaram correlação muito forte $(r \geq 0,9)$. Em contrapartida, para o período chuvoso, notou-se que $80 \%$ dos apresentaram valores significativos, sendo $37,6 \%$ com correlações fortes entre si enquanto $22 \%$ apresentaram correlação muito forte.

Durante os dois períodos os sólidos totais dissolvidos e condutividade elétrica apresentaram alta correção entre si ( $r=0,98$ estiagem e $r=0,99$ chuvoso). Durante a estiagem, nitrito, FT e CT apresentaram correlação nula $(r=0,00)$. Contrastando com a estação chuvosa, onde esses parâmetros apresentaram correlação perfeita positiva $(r=1,00)$. Souza et al. (2017) constatou a existência de correlações entre nitrito, 
FT e CT e a justificaram como resultado do despejo de esgoto doméstico na água e/ou sedimentos resuspensos.

Tabela 4: Matriz de correlação de Pearson e coeficientes significativos para os parâmetros de qualidade da água do Meio do Córrego Fortaleza. Apenas correlações fortes e muito fortes positivas $(r \geq 0,6)$.

\begin{tabular}{|c|c|c|c|c|c|c|c|c|c|c|c|c|c|c|c|c|c|c|}
\hline & & $T$ & STD & $C E$ & $S T$ & Cor & Turb & $p H$ & $O D$ & $D B O$ & $D Q O$ & $A / c$ & $\mathrm{NO}_{2}^{-}$ & $\mathrm{NO}_{3}^{-}$ & $\boldsymbol{N} T$ & $F T$ & $C T$ & E. Coli \\
\hline \multirow{2}{*}{$T$} & $E$ & 1,00 & & & & & & & & & & & & & & & & \\
\hline & $C$ & 1,00 & & & & & & & & & & & & & & & & \\
\hline \multirow{2}{*}{ STD } & $E$ & - & 1,00 & & & & & & & & & & & & & & & \\
\hline & $C$ & - & 1,00 & & & & & & & & & & & & & & & \\
\hline \multirow{2}{*}{$C E$} & $E$ & - & 0,98 & 1,00 & & & & & & & & & & & & & & \\
\hline & C & - & 0,98 & 1,00 & & & & & & & & & & & & & & \\
\hline \multirow{2}{*}{$S T$} & $E$ & - & - & - & 1,00 & & & & & & & & & & & & & \\
\hline & $C$ & - & - & - & 1,00 & & & & & & & & & & & & & \\
\hline \multirow{2}{*}{ Cor } & $E$ & 0,71 & - & - & - & 1,00 & & & & & & & & & & & & \\
\hline & $C$ & - & - & - & - & 1,00 & & & & & & & & & & & & \\
\hline \multirow{2}{*}{ Turb } & $E$ & - & - & - & - & 0,82 & 1,00 & & & & & & & & & & & \\
\hline & $C$ & - & - & - & - & - & 1,00 & & & & & & & & & & & \\
\hline \multirow{2}{*}{$p H$} & $E$ & - & - & - & 0,91 & - & - & 1,00 & & & & & & & & & & \\
\hline & $C$ & - & - & - & 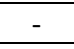 & 0,86 & - & 1,00 & & & & & & & & & & \\
\hline \multirow{2}{*}{$O D$} & $E$ & - & - & - & 0,88 & - & - & - & 1,00 & & & & & & & & & \\
\hline & $C$ & - & - & - & - & 0,61 & - & 0,68 & 1,00 & & & & & & & & & \\
\hline \multirow{2}{*}{$D B O$} & $E$ & - & - & - & - & - & - & - & - & 1,00 & & & & & & & & \\
\hline & $C$ & - & 0,82 & 0,79 & - & - & - & - & - & 1,00 & & & & & & & & \\
\hline \multirow{2}{*}{$D Q O$} & $E$ & - & 0,98 & 0,96 & - & - & - & - & - & - & 1,00 & & & & & & & \\
\hline & $C$ & - & - & 0,70 & - & - & - & - & - & - & 1,00 & & & & & & & \\
\hline \multirow{2}{*}{ Alcal. } & $E$ & - & - & - & 0,71 & - & 0,68 & - & - & 0,93 & - & 1,00 & & & & & & \\
\hline & $C$ & - & - & - & - & - & - & - & 0,69 & - & - & 1,00 & & & & & & \\
\hline \multirow{2}{*}{$\mathrm{NO}_{2}^{-}$} & $E$ & 1,00 & - & - & - & 1,00 & 0,68 & - & - & - & - & - & 1,00 & & & & & \\
\hline & $c$ & - & - & - & 0,91 & - & - & - & - & - & 0,67 & 0,66 & 1,00 & & & & & \\
\hline \multirow{2}{*}{$\mathrm{NO}_{3}^{-}$} & $E$ & - & - & - & - & - & 0,83 & - & - & 0,99 & - & 0,97 & - & 1,00 & & & & \\
\hline & $C$ & - & - & - & - & - & 0,72 & - & - & - & 1,00 & - & - & 1,00 & & & & \\
\hline \multirow{2}{*}{$N T$} & $E$ & 0,63 & 0,94 & 0,90 & - & - & - & - & - & - & 0,98 & - & 0,60 & - & 1,00 & & & \\
\hline & $C$ & 0,94 & - & - & - & - & - & - & - & - & - & - & - & - & 1,00 & & & \\
\hline \multirow{2}{*}{$F T$} & $E$ & - & 1,00 & 1,00 & - & - & - & - & - & - & 0,98 & - & - & - & 0,93 & 1,00 & & \\
\hline & C & - & 0,74 & 0,69 & - & - & - & - & - & 1,00 & - & - & - & - & - & 1,00 & & \\
\hline \multirow{2}{*}{ C.T } & $E$ & - & - & - & 1,00 & - & - & 0,87 & 0,83 & - & - & 0,77 & - & 0,60 & - & - & 1,00 & \\
\hline & $C$ & 0,87 & - & - & 1,00 & - & - & - & - & - & - & 1,00 & 0,97 & 0,69 & - & 1,00 & 1,00 & \\
\hline \multirow{2}{*}{ E. Coli } & $E$ & 0,72 & 0,88 & 0,83 & - & 0,64 & - & - & - & - & 0,95 & - & 0,69 & - & 0,99 & 0,88 & - & 1,00 \\
\hline & $C$ & 0,86 & - & - & 1,00 & - & - & - & - & - & - & 1,00 & 0,97 & 0,69 & - & 1,00 & 1,00 & 1,00 \\
\hline
\end{tabular}

Legenda: E: Estiagem; C: Chuvoso; T: Temperatura; STD: Sólidos Dissolvidos Totais; CE: Condutividade Elétrica; ST: Sólidos Totais; Turb: Turbidez; OD: Oxigênio Dissolvido; $\mathrm{DBO}_{5}$ : Demanda Bioquímica de Oxigênio; DQO: Demanda Química de Oxigênio; Alc: Alcalinidade; $\mathrm{NO}_{2}$ : Nitrito, $\mathrm{NO}_{3}$ : Nitrato; NT: Nitrogênio Total; FT: Fósforo Total; $\mathrm{CT}$ : Coliformes Totais.

Tabela 5: Matriz de correlação de Pearson e coeficientes significativos para os parâmetros de qualidade da água do Exutório do Córrego Fortaleza. Apenas correlações fortes e muito fortes positivas $(r \geq 0,6)$.

\begin{tabular}{|c|c|c|c|c|c|c|c|c|c|c|c|c|c|c|c|c|c|c|}
\hline & & $T$ & STD & $C E$ & $S T$ & Cor & Turb & $p H$ & $O D$ & $D B O$ & DQO & $A / c$ & $\mathrm{NO}_{2}^{-}$ & $\mathrm{NO}_{3}^{-}$ & $N T$ & $F T$ & $C T$ & E. Coli \\
\hline \multirow{2}{*}{$T$} & $E$ & 1,00 & & & & & & & & & & & & & & & & \\
\hline & $C$ & 1,00 & & & & & & & & & & & & & & & & \\
\hline \multirow{2}{*}{ STD } & $E$ & - & 1,00 & & & & & & & & & & & & & & & \\
\hline & $C$ & - & 1,00 & & & & & & & & & & & & & & & \\
\hline \multirow{2}{*}{$C E$} & $E$ & - & 0,99 & 1,00 & & & & & & & & & & & & & & \\
\hline & C & - & 0,98 & 1,00 & & & & & & & & & & & & & & \\
\hline \multirow{2}{*}{$S T$} & $E$ & - & - & - & 1,00 & & & & & & & & & & & & & \\
\hline & $C$ & - & - & - & 1,00 & & & & & & & & & & & & & \\
\hline \multirow{2}{*}{ Cor } & $E$ & 0,72 & 0,84 & 0,74 & - & 1,00 & & & & & & & & & & & & \\
\hline & $C$ & - & 0,92 & 0,88 & - & 1,00 & & & & & & & & & & & & \\
\hline \multirow{2}{*}{ Turb } & $E$ & 0,80 & 0,80 & 0,69 & - & 0,99 & 1,00 & & & & & & & & & & & \\
\hline & $C$ & - & - & - & - & - & 1,00 & & & & & & & & & & & \\
\hline \multirow{2}{*}{$p H$} & $E$ & - & - & - & 0,99 & - & - & 1,00 & & & & & & & & & & \\
\hline & $C$ & - & 0,63 & 0,70 & - & 0,73 & - & 1,00 & & & & & & & & & & \\
\hline$O D$ & $E$ & - & - & - & 0,95 & - & - & - & 1,00 & & & & & & & & & \\
\hline
\end{tabular}




\begin{tabular}{|c|c|c|c|c|c|c|c|c|c|c|c|c|c|c|c|c|c|c|}
\hline & $C$ & - & - & - & - & - & - & - & 1,00 & & & & & & & & & \\
\hline \multirow{2}{*}{$D B O$} & $E$ & - & - & - & - & - & - & - & - & 1,00 & & & & & & & & \\
\hline & $C$ & - & - & - & - & - & - & - & - & 1,00 & & & & & & & & \\
\hline \multirow{2}{*}{$D Q O$} & $E$ & 0,82 & 0,85 & 0,77 & - & 0,95 & 0,90 & - & - & - & 1,00 & & & & & & & \\
\hline & $C$ & - & - & - & - & - & - & - & - & - & 1,00 & & & & & & & \\
\hline \multirow{2}{*}{ Alcal. } & $E$ & - & - & - & 0,74 & - & - & 0,62 & - & 0,88 & - & 1,00 & & & & & & \\
\hline & $C$ & - & - & - & 0,60 & - & - & - & 0,97 & - & - & 1,00 & & & & & & \\
\hline \multirow{2}{*}{$\mathrm{NO}_{2}^{-}$} & $E$ & 0,96 & - & - & - & 0,85 & 0,90 & - & - & - & 0,63 & - & 1,00 & & & & & \\
\hline & $C$ & - & - & - & 0,86 & - & - & - & - & - & - & 0,65 & 1,00 & & & & & \\
\hline \multirow{2}{*}{$\mathrm{NO}_{3}^{-}$} & $E$ & - & - & - & 0,86 & - & - & 0,93 & 0,98 & - & - & - & - & 1,00 & & & & \\
\hline & $C$ & - & - & - & - & - & 0,65 & - & - & - & 0,98 & - & - & 1,00 & & & & \\
\hline \multirow{2}{*}{$N T$} & $E$ & 0,85 & 0,82 & 0,72 & - & 0,97 & 0,93 & - & - & - & 1,00 & - & 0,68 & - & 1,00 & & & \\
\hline & $C$ & 0,83 & 0,80 & 0,79 & - & 0,87 & 0,70 & - & - & - & - & - & - & - & 1,00 & & & \\
\hline \multirow{2}{*}{$F T$} & $E$ & 0,99 & - & - & - & 0,99 & 1,00 & - & - & - & 0,88 & - & 0,92 & - & 0,91 & 1,00 & & \\
\hline & $C$ & - & - & - & - & - & - & 0,76 & - & 0,91 & - & - & - & - & - & 1,00 & & \\
\hline \multirow{2}{*}{ C.T } & $E$ & 0,78 & 0,89 & 0,81 & - & 0,92 & 0,87 & - & - & - & 1,00 & - & - & - & 0,99 & 0,85 & 1,00 & \\
\hline & $C$ & - & - & - & 1,00 & - & - & - & - & - & - & 0,60 & - & - & - & 0,68 & 1,00 & \\
\hline \multirow{2}{*}{ E. Coli } & $E$ & 0,78 & 0,89 & 0,81 & - & 0,92 & 0,87 & - & - & - & 1,00 & - & - & - & 0,99 & 0,85 & 1,00 & 1,00 \\
\hline & $C$ & - & - & - & 1,00 & - & - & - & - & - & - & 0,60 & - & - & - & 0,68 & 1,00 & 1,00 \\
\hline
\end{tabular}

Legenda: E: Estiagem; C: Chuvoso; T: Temperatura; STD: Sólidos Dissolvidos Totais; CE: Condutividade Elétrica; ST: Sólidos Totais; Turb: Turbidez; OD: Oxigênio Dissolvido; $\mathrm{DBO}_{5}$ : Demanda Bioquímica de Oxigênio; DQO: Demanda Química de Oxigênio; Alc: Alcalinidade; $\mathrm{NO}_{2}$ : Nitrito, $\mathrm{NO}_{3}$ : Nitrato; NT: Nitrogênio Total; FT: Fósforo Total; $\mathrm{CT}$ : Coliformes Totais.

Para o meio e o exutório durante a estiagem houve $80,8 \%$ e $91 \%$ de coeficientes significativos, respectivamente. Sendo que para o meio, $32,7 \%$ dos coeficientes significativos foram de correlações muito forte. No exutório, esse percentual foi de $40,3 \%$. No período chuvoso, os valores de coeficientes significativos foram iguais nos dois pontos: $76,5 \%$. Destes, $27 \%$ foram de correlação muito forte no meio e $18,3 \%$ no exutório. O meio e o exutório apresentaram comportamento semelhante em seus coeficientes nos dois períodos avaliados. Durante a estiagem, tanto o meio quanto o exutório apresentaram correlações muito fortes para os seguintes parâmetros: TempxNitrito, STDxCE, STxpH, DQOxNT e NTxFT. No período chuvoso, os dois pontos apresentaram as seguintes correlações muito fortes: STDxCE, STxCT, DBO ${ }_{5} \mathrm{xFT}, \mathrm{CT} \times$ E. coli.

Souza et al. (2014) salienta que a correlação CT e E. coli geralmente aumenta com a vazão e com os eventos de precipitação, o que explica o fato de no período chuvoso esses parâmetros terem apresentado correlação perfeita nos no meio e no exutório do córrego. Em todos os pontos amostrais, nos dois períodos STD e CE apresentaram correlação muito forte positiva. Isso porque a condutividade elétrica representa a concentração de íons, estando, portanto, associada à concentração de sólidos dissolvidos totais (BERGER et al., 2013). Ribeiro et al. (2016) sugerem a alta correlação entre essas duas variáveis é resultado da contribuição de efluentes domésticos ao longo do corpo d'água.

\section{Classificação pelo método IQA}

Os valores de IQA calculados para os pontos amostrais são apresentados na tabela 6. De forma geral, a qualidade das águas do Córrego Fortaleza, segundo os valores do IQA, é considerada na categoria "Ruim". Quase todos os trechos apresentaram qualidade ruim, à exceção da nascente, que apresentou qualidade razoável na maior parte do período de monitoramento.

Conforme os dados apresentados na tabela 6, observa-se que no início período de chuvas, as águas estiveram com qualidade inferior às águas do período de estiagem. Piratoba et al. (2017) encontrou situação semelhante em avaliação da qualidade da água da área portuária de Barcarena (PA). Piratoba et al. (2017) 
explicam que essa diferença pode ser devida à sazonalidade, uma vez que maiores níveis pluviométricos implicam em maiores teores de poluentes, sendo carreados pela chuva do solo em direção ao rio.

Tabela 6: Faixas de IQA para o Córrego Fortaleza obtidas durante o período de monitoramento.

\begin{tabular}{|c|l|l|l|l|}
\hline \multicolumn{5}{|c|}{ IQA - Córrego Fortaleza } \\
\hline Mês & Estação & \multicolumn{1}{|c|}{ Nascente } & \multicolumn{1}{c|}{ Meio } \\
\hline Jul/17 & Estiagem & 60 RAZOÁVEL & 40 RUIM & 43 RUIM \\
\hline Set/17 & Estiagem & 59 RAZOÁVEL & 28 RUIM & 27 RUIM \\
\hline Nov/17 & Chuvoso & 42 RUIM & 23 PÉSSIMA & 25 PÉSSIMA \\
\hline Jan/18 & Chuvoso & 60 RAZOÁVEL & 44 RUIM & 42 RUIM \\
\hline
\end{tabular}

As variáveis que colaboraram com a redução dos valores de IQA no período chuvoso (nov/17), foram cor, $\mathrm{DBO}_{5}$, nitrogênio total, fósforo total e E. coli. Barros et al. (2011) encontrou resultados semelhantes para o Córrego André, em Mirassol D’Oeste, MT, onde as principais responsáveis pela diminuição da qualidade da água foram $\mathrm{OD}, \mathrm{DBO}_{5}, E$. coli, e fósforo total.

\section{CONSIDERAÇÕES FINAIS}

A partir dos resultados obtidos, conclui-se que as águas superficiais do Córrego Fortaleza estão sensivelmente prejudicadas devido a atividades antrópicas na microbacia decorrentes do uso e ocupação desordenados do solo. Percebe-se, por meio da aplicação do IQA, que quase todos os trechos apresentaram qualidade 'ruim', à exceção da nascente, que apresentou qualidade 'razoável' na maior parte do período de monitoramento.

Conclui-se também que a influência da sazonalidade climática é fator importante na qualidade das águas do Córrego e que esta exerce influência na forma como os parâmetros de qualidade se correlacionam. A transição do período de estiagem para o período de chuvas, colaborou com o aumento das concentrações de $\mathrm{DBO}_{5}$, cor, nitrogênio total, fósforo total e $E$. coli, o ocasionou na redução dos valores de IQA nos pontos amostrados. Recomenda-se melhorias no sistema de esgotamento sanitário e no manejo do solo da microbacia do Córrego Fortaleza por meio de ações de gestão, a fim de alcançar melhores índices de qualidade da água e, com isso, melhores condições de vida à população e aos ecossistemas locais.

\section{REFERÊNCIAS}

ALMEIDA, C. O. S.; AMORIM, S. S. R.; COUTO, E. G.; ELTZ, F. L. F.; BORGES, L. E. C.. Potencial erosivo da chuva de Cuiabá, MT: distribuição e correlação com a precipitação pluviométrica. Revista Brasileira de Engenharia Agrícola e Ambiental, v.15, n.2, p.178-184, 2011. DOI: http://doi.org/10.1590/s1415-43662011000200011

AMORIM, D. G; CAVALCANTE, P. R. S.; SOARES, L. S.; AMORIM, P. E. C.. Enquadramento e avaliação do índice de qualidade da água dos igarapés Rabo de Porco e Precuá, localizados na área da Refinaria Premium I, município de Bacabeira (MA). Engenharia Sanitária e Ambiental, v.22, n.2, p.251-259, 2016. DOI: http://doi.org/10.1590/s1413$\underline{41522016131212}$
APHA. American Public Health Association. Standard Methods for the Examination of Water and Wastewater. 22 ed. Washington: APHA, 2012.

BARROS, R. V. G.; SOUZA, H. M. L.; SOUZA, C. A..

Determinação do índice de qualidade da água (IQA) na subbacia do córrego André em Mirassol d'oeste, Mato Grosso. Engenharia Ambiental: Pesquisa e Tecnologia, Espírito Santo do Pinhal, v.8, n.3, p.138-153, 2011.

BERGER, J. S.; HERMES, E.; ZENATTI, D. C.; GONÇALVES, M. P.; LINS, M. A.; WULF, V. S.. Relação entre Série de Sólidos e Condutividade Elétrica em Biodigestor Tubular Utilizado no Tratamento de Efluente de Amidonaria. Scientia Agraria Paranaensis, v.12, p.377-383, 2013. DOI:

http://doi.org/10.18188/1983-1471/sap.v12nsupp377-383 
BRASIL. Resolução CONAMA n.357 de 17 de março de 2005. Brasília: MMA, 2005

CALLEGARI-JACQUES, S. M.. Bioestatística: princípios e aplicações. Porto Alegre: Artmed, 2003.

CASTRO, L. M. A.; BAPTISTA, M. B.; BARRAUD, S.. Proposição de metodologia para avaliação dos efeitos da urbanização nos corpos de água. Revista Brasileira de Recursos Hídricos, v.14, n.4, p.113-123, 2009. DOI:

http://doi.org/10.21168/rbrh.v14n4.p113-123

CETESB. Companhia Ambiental do Estado de São Paulo. Guia nacional de coleta e preservação de amostras: água, sedimento, comunidades aquáticas e efluentes líquidas. São Paulo: CETESB, 2011

CHIARANDA, R.; COLPINI, C.; SOARES, T. S.. Caracterização da Bacia Hidrográfica do Rio Cuiabá. Advances In Forestry Science, Cuiabá, v.3, n.1, p.13-20, 2016.

CORADI, P. C.; FIA, R.; PEREIRA-RAMIREZ, O.. Avaliação da qualidade da água superficial dos cursos de água do município de Pelotas-RS, Brasil. Ambiente e Água: An Interdisciplinary Journal of Applied Science, v.4, n.2, p.4656, 2009. DOI: http://doi.org/10.4136/ambi-agua. 85

FIA, R.; TADEU, H. C.; MENEZES, J. P. C.; FIA, F. R. L.; OLIVEIRA, L. F. C.. Qualidade da água de um ecossistema lótico urbano. Revista Brasileira de Recursos Hídricos, v.20, n.1, p.267-275, 2015. DOI:

http://doi.org/10.21168/rbrh.v20n1.p267-275

GARCIA, S. M. N. P.. The master plans and planning urban of agglomerate Cuiabá/Várzea Grande-MT. Dissertação (Mestrado em Planejamento Urbano e Regional) Universidade de São Paulo, São Paulo, 2010.

JORDÃO, E. P.; PESSÔA, C.. Tratamento de esgotos domésticos. 7 ed. Pinheiros: Abes, 2014.

MATO GROSSO. Relatório de Monitoramento da Qualidade da Água da Região Hidrográfica do Paraguai: 2012-2014. Cuiabá: SEMA, 2016.

MEDEIROS, S. R. M.; BITTENCOURT, R. P.; FARIAS, M. S.; BELLO, I. P.; FIA, R.; OLIVEIRA, L. F. C.. Índice de qualidade das águas e balneabilidade no Riacho da Bica, Portalegre, RN, Brasil. Ambiente e Água: An Interdisciplinary Journal of Applied Science, v.11, n.3, p.711-730, 2016. DOI: http://doi.org/10.4136/ambi-agua.1833

MENEZES, J. P. C, BITTENCOURT, R. P.; FARIAS, M. S.; BELLO, I. P.; FIA, R.; OLIVEIRA, L. F. C.. Relação entre padrões de uso e ocupação do solo e qualidade da água em uma bacia hidrográfica urbana. Engenharia Sanitária e Ambiental, v.21, n.3, p.519-534, 2016. DOI: http://doi.org/10.1590/s141341522016145405

MENEZES, J. P. C.; BERTOSSI, A. P. A.; SANTOS, A. R.; NEVES, M. A.. Correlação entre uso da terra e qualidade da água subterrânea. Engenharia Sanitária e Ambiental, v.19, n.2, p.173-186, 2014. DOI: http://doi.org/10.1590/s1413$\underline{41522014000200008}$

PIRATOBA, A. R. A.; RIBEIRO, H. M. C.; MORALES, G. P.; GONÇALVES, W. G.. Caracterização de parâmetros de qualidade da água na área portuária de Barcarena, PA, Brasil. Ambiente e Água: An Interdisciplinary Journal of Applied Science, v.12, n.3, p.435-456, 2017. DOI: http://doi.org/10.4136/ambi-agua.1910

RIBEIRO, T. G.; BOAVENTURA, G. R.; CUNHA, L. S.; PIMENTA, S. M.. Estudo da qualidade das águas por meio da correlação de parâmetros físico-químicos, Bacia Hidrográfica do Ribeirão Anicuns. Geochimica Brasiliensis, v.30, n.1, p.84-94, 2016. DOI: http://doi.org/10.21715/gb23582812.2016301084

RICHTER, C. A.. Água: Métodos e Tecnologia de Tratamento. São Paulo: Blucher, 2009.

SOUZA, A.; BERTOSSI, A. P. A.; LASTORIA, G.. Diagnóstico temporal e espacial da qualidade das águas superficiais do Córrego Bandeira, Campo Grande, MS. Revista Agro@mbiente,v.9, n.3, p.227-234, 2015. DOI: http://doi.org/10.18227/1982-8470ragro.v9i3.2312

SOUZA, C. A.; SANTOS, S. M.; COSTA, R. A.; OLIVEIRA, W. A.; SCALIZE, P. S.. Correlação entre variáveis abióticas e biótica em água de abastecimento público em Goiás. In: CONGRESSO ABES/FENASAN, 29. Anais. São Paulo: Abes, 2017.

SOUZA, M. M.; GASTALDINI, M. C. C.. Avaliação da qualidade da água em bacias hidrográficas com diferentes impactos antrópicos. Engenharia Sanitária e Ambiental, v.19, n.3, p.263-274, 2014. DOI: http://doi.org/10.1590/s1413$\underline{41522014019000001097}$

VAZ, S. R.; MELO, W. R. F.; SOUZA, J. A. R.. Influência da sazonalidade climática na qualidade da água do Rio Xopotó em Guidorval-MG. In: CONGRESSO BRASILEIRO DE GESTÃO AMBIENTAL, 5. Anais. Bauru: IBEAS, 2014.

YU, D.; SHI, P.; LIU, Y.; XUN, B.. Detecting land use-water quality relationships from the viewpoint of ecological restoration in na urban area. Ecological Engineering, v. 53 p.205-216, 2013. DOI:

http://doi.org/10.1016/j.ecoleng.2012.12.045

A CBPC - Companhia Brasileira de Produção Científica (CNPJ: 11.221.422/0001-03) detém os direitos materiais desta publicação. Os direitos referem-se à publicação do trabalho em qualquer parte do mundo, incluindo os direitos às renovaç̃̃es, expansões e disseminaç̃es da contribuiç̃o, bem como outros direitos subsidiários. Todos os trabalhos publicados eletronicamente poderão posteriormente ser publicados em coletâneas impressas sob coordenação da Sustenere Publishing da Companhia Brasileira de Produção Científica e seus parceiros autorizados. Os (as) autores (as) preservam os direitos autorais, mas não têm permissão para a publicação da contribuição em outro meio, impresso ou digital, em português ou em tradução. 